\title{
SUÁREZ, HUGO JOSÉ. CREYENTES URBANOS: SOCIOLOGÍA DE LA EXPERIENCIA RELIGIOSA EN UNA COLONIA POPULAR DE LA CIUDAD DE MÉXICO. MÉXICO: UNIVERSIDAD NACIONAL AUTÓNOMA DE MÉXICO, 2015.
}

\section{Karina Bárcenas Barajas ${ }^{1}$}

Cualquier teoría general de la ciudad debe de alguna manera relacionar los procesos sociales en la ciudad con la forma espacial que asume. En términos disciplinarios, esto equivale a integrar dos importantes tradiciones educativas y de investigación - lo llamo construir un puente entre los poseedores de la imaginación sociológica y aquellos imbuidos de una conciencia espacial o una imaginación geográfica.

David Harvey ${ }^{2}$

En su obra Creyentes Urbanos, Hugo José Suárez conjuga la imaginación sociológica y la imaginación geográfica para situarse en un escenario de la Ciudad de México, la colonia Ajusco, que representa un gran espacio de observación de lo religioso y de la vida social en general por su constitución como un territorio y por su dinámica cultural suburbana. Como lo señala el autor, "en un terreno de piedras, se tuvo que construir una sociedad con todo lo que ello implica: traer sus dioses y demonios, relacionarse con el Estado, construir sociedad y hacer, de y entre lava volcánica un 'lugar" (Suárez, 2015, p. 16).

A partir de la dinámica sociocultural suburbana del Ajusco el autor dialoga con las grandes transformaciones que han marcado la dinámica del campo religioso en las últimas décadas: la diversidad religiosa, los procesos de institucionalización y desinstitucionalización religiosa y la individua-

1 Dra. en Ciencias Sociales con Especialidad en Antropología Social. Investigadora Asociada en el Instituto de Investigaciones Sociales de la Universidad Nacional Autónoma de México (UNAM). Contacto: kb.barcenas@gmail.com

2 Harvey (2009, p. 23). 
lización de las creencias. Dichos procesos han impactado en la manera cómo los creyentes en la colonia Ajusco viven su religiosidad y configuran su identidad religiosa, por lo que, desde esta perspectiva el autor coloca la mirada en el sujeto creyente, sin desatender el análisis del campo religioso.

Fiel a su habitus sociológico, Hugo José Suárez construye una sociología de los creyentes que le permite analizar la composición del campo religioso en un diálogo que prioriza las estructuras y la oferta religiosa local, enraizada en la colonia Ajusco, pero manteniendo una relación constante con los debates globales sobre la creencia y la pertenencia religiosa.

La estructura del libro se compone de tres partes que van de la deconstrucción de un modo de observación de lo religioso a el análisis del territorio, el campo y las disposiciones e individuación de los creyentes. En la primera parte, El punto de vista, Hugo José Suárez presenta un gran trabajo de deconstrucción de su modo de observación de lo religioso en el que siguiendo a Max Weber plantea su interés por "lo pragmático de las religiones" por sus formas históricas, por la "diversidad polifacética de sus condiciones" (Suárez, 2015, p. 32).

Desde esta perspectiva es que dicho modo de observación de lo religioso prioriza la experiencia de los creyentes, "sus maneras de encontrar respuestas religiosas en la vida diaria [...] sus disposiciones para dar sentido a sus prácticas" (Suárez, 2015, p. 34), o como lo plantea el autor en términos de Pierre Bourdieu "los habitus religiosos individuales" (Suárez, 2015, p. 38). Si consideramos que tanto la experiencia como el individuo son centrales para la sociología contemporánea, podemos plantear que la obra Creyentes Urbanos aporta una perspectiva importante para situarse en estos debates.

La observación sobre lo religioso del autor incorpora un análisis de los grandes desplazamientos teóricos para explicar el comportamiento religioso en México: "de la disidencia a la mutación, de la mutación a la diversidad, [y] de la diversidad a la pluralidad en la diversidad" (Suárez, 2015, p. 47), así como las particularidades históricas de la colonia Ajusco que, desde su perspectiva, responden a "una compleja articulación de lógicas heredadas 
de la cultura campesina migrante en la ciudad, pueblos originarios cercanos, y dinámicas tradicionalmente urbanas y modernas" (Suárez, 2015, p. 59).

En la segunda parte, Territorio, campo y orientaciones religiosas, Hugo José Suárez responde sociológicamente a la interrogante “¿Cómo se construye un territorio y en él una sociedad local?” (Suárez, 2015, p. 69). Además, los lectores encontrarán un panorama sobre la composición del campo religioso en la colonia Ajusco, del cual se desprenden cuatro maneras de creer:

1. Los tradicionales institucionalizados, que cumplen con las leyes y obligaciones y que participan en la vida eclesial.

2. Los tradicionales desinstitucionalizados, que consideran que para ser buen creyente no es necesario ni cumplir con los deberes religiosos, ni conocer con mayor profundidad la doctrina católica.

3. Los innovadores institucionales, que tienen una relación estrecha con la institución - la necesitan y participan en ella - pero no acatan los mandatos oficiales.

4. Los innovadores autónomos, que creen a su manera lejos de la iglesia y no tienen preocupación por la doctrina, los más jóvenes se ubican en esta categoría (Suárez, 2015, p. 171, 177).

La tercera parte, Disposición e individuación: los creyentes, se inscribe en las lógicas de la heterodoxia y la heterogeneidad, es decir en los procesos de diferenciación al interior del catolicismo y en lo que el autor denomina "creencias bisagra" (Suárez, 2015, p. 174), que articulan las creencias tradicionales con las nuevas creencias, como la religiosidad popular, las religiones emergentes, como la santería y la Santa Muerte. Dicha heterodoxia y heterogeneidad también está en relación con las variables género y generación, las cuales son "determinante[s] en la experiencia religiosa" (Suárez, 2015, p. 55).

Finalmente, si consideramos que la versión impresa del libro incluye un $\mathrm{CD}$ que mediante una estructura de página web muestra, como lo señala el autor, "otra[s] ruta[s] para adentrarse en las dinámicas religiosas" se puede plantear que la sociología de los creyentes de Hugo José Suárez se presenta a 
los lectores a través de una narrativa transmedia, que de acuerdo con Carlos Scolari (2013) ocurre cuando una historia es contada a través de diversos medios o plataformas tecnológicas.

El contenido del CD también se puede consultar en el sitio web de Creyentes Urbanos ${ }^{3}$. En ambos soportes tecnológicos, la sociología de los creyentes se muestra a través de una cartografía de la colonia Ajusco, con las rutas y mapas de las peregrinaciones, series fotográficas sobre la diversidad de expresiones religiosas en el Ajusco, videos en los que la voz del autor nos sitúa en otra perspectiva religiosa y territorial del Ajusco, así como la base de datos de la Encuesta de la Experiencia Religiosa en la Colonia Ajusco.

Creyentes urbanos es una obra altamente recomendable para todos los interesados en la experiencia religiosa de los creyentes y en las grandes transformaciones del campo religioso en México ocurridas durante las últimas décadas, a través de una narrativa dirigida por la voz del investigador pero que también privilegia la voz de sus informantes.

\section{REFERENCIAS}

HARVEY, David. Social Justice and The City. Atenas: The University of Georgia Press, 2009.

SCOLARI, Carlos. Narrativas Transmedia: cuando todos los medios se encuentran. Barcelona: Deusto, 2013.

SUÁREZ, Hugo José. Creyentes urbanos: Sociología de la experiencia religiosa en una colonia popular de la Ciudad de México. Ciudad de México: Universidad Nacional Autónoma de México, 2015.

Recebido em: 03/01/17

Aprovado em: 04/02/17

3 Disponível em: <http://creyentesurbanos.com>. Acesso em: 4 jan. 2017. 